Manchester Journal of International Economic Law

Volume 18, Issue 2: 192-204, 2021

\title{
Are IPRs and Patents the Real Barriers to COVID-19 Vaccine Supplies?
}

\author{
Van Anh Le* and Leah Samson**
}

\begin{abstract}
In less than a year since the WHO's declaration of COVID-19 as a global pandemic, thirteen vaccines against COVID-19 have been approved in at least one jurisdiction. However, new challenges have arisen, mostly surrounding the global distribution and access to these vaccines, particularly for low and middleincome countries. The Intellectual Property (IP) Rights, mainly patents, have been accused of standing in the way of global vaccination supplies.

By adopting an evidence-based approach, this paper challenged such current (mis)belief, arguing that the roadblocks of the inoculation program have nothing to do with IP Rights, but the real bottlenecks instead lie in manufacturing capacity, supply chain and export restrictions issues. The idea that vaccines will be made cheaper and quicker by removing the patent system and other forms of IP Rights is both erroneous and unfounded. The authors further argued that eroding patent protection does more harm than good. Firstly, it will disincentivise research and development $(R \& D)$ in the vaccine industry, one of the most challenging sectors. Secondly, if patented vaccines are in the public domain and are not properly allocated, the ripple effect of the tragedy of common goods will soon be felt. Finally, removing IP rules can cause an increase in counterfeit products.
\end{abstract}

Therefore, less time should be spent on trying to dismantle the patent system. Instead, the focus should be on addressing trade restrictions, improving the global manufacturing partnerships between vaccine developers, and strengthening their cross-border supply chains to re-unite a fragmented world.

\section{INTRODUCTION}

On 31 December 2019, the World Health Organization (WHO) China Country Office was informed of cases of pneumonia of unknown etiology (unknown cause) detected in Wuhan City, Hubei Province of China. ${ }^{1}$ One month later, on 30 January 2020, the WHO announced a related public health emergency of international concern. ${ }^{2}$ On 11 March 2020, the WHO declared the coronavirus disease 2019 (COVID-19)

\footnotetext{
*Van Anh Le is a Departmental Lecturer in Intellectual Property law at the University of Oxford, UK. Email: van.le@law.ox.ac.uk. ** Leah Samson is a paralegal at Tozers Solicitors in Exeter. Email: Leahsamson11@gmail.com.

We would like to express our sincere gratitude to Sir Robin Jacob of UCL, Professor Martin Adelman of George Washington University and Dr Andi Hoxhaj of University of Warwick for their constructive comments and support during the writing of this article.

1 'Listings of WHO's response to COVID-19' (WHO, 29 June 2020, last updated on 28 December 2020) https://www.who.int/news/item/29-06-2020-covidtimeline (accessed 26 March 2021).

${ }^{2}$ Ibid.
} 
to be a global pandemic. ${ }^{3}$ In November 2020, three pharmaceuticals Pfizer-BioNTech, ${ }^{4}$ Moderna, ${ }^{5}$ and AstraZeneca ${ }^{6}$ announced successful third stage trial results for their respective COVID-19 vaccine candidates. On 8 December 2020, the UK was the first country to start vaccinating its own population, marking the country's biggest vaccine campaign in history. ${ }^{7}$ So far, in less than a year since the WHO's declaration of COVID-19 as a global pandemic, thirteen vaccines against COVID-19 have been approved in at least one jurisdiction. ${ }^{8}$ This is a truly tremendous achievement if we compare it to the considerable time of 10 to 15 years to develop a new vaccine from scratch for most diseases.

However, new challenges have arisen, mostly surrounding the global distribution and access to these vaccines, particularly for low and middle-income countries. IP Rights have been accused of standing in the way of global vaccination supplies. ${ }^{9}$ In early October 2020, an initiative, led by India and South Africa, has called for a temporary waiver of IP Rights including patents, copyrights, industrial designs, and undisclosed information (trade secrets) in relation to the "prevention, containment or treatment of COVID-19 ... until widespread vaccination is in place globally, and the majority of the world's population has developed immunity." ${ }^{10}$ Such a waiver aims at a wide range of "medical products including vaccines and medicines or to scaling-up of research, development, manufacturing and supply of medical products essential to combat COVID-19". ${ }^{11}$

The waiver proposal, which was tabled at the World Trade Organisation (WTO)'s Trade-Related Aspects of Intellectual Property (TRIPS) Council, is ambitious but ambiguous at the same time as we do not know when the world will reach a herd immunity threshold or whether we will ever be there at all, given the unpredictable factors of virus mutation and human behaviours. For example, in the UK, the rapid rise of the Delta variant further complicates the country's calculations about herd immunity. ${ }^{12}$ Since it is uncertain as to when the world will reach the herd immunity threshold, if accepted, this waiver proposal could be a slippery slope. This idea can become a "new normality" where the matter of IP protection related to COVID-

\footnotetext{
${ }^{3}$ Ibid.

4 'Pfizer and BioNTech Announce Vaccine Candidate Against Covid-19 Achieved Success in First Interim Analysis From Phase 3 Study' (Pfizer, Press Release on 9 November 2020) https://www.pfizer.com/news/press-release/press-release-detail/pfizer-andbiontech-announce-vaccine-candidate-against (accessed 26 March 2021).

5 'Moderna's COVID-19 Vaccine Candidate Meets its Primary Efficacy Endpoint in the First Interim Analysis of the Phase 3 COVE Study' (Moderna, Press Release on 16 November 2020) https://investors.modernatx.com/news-releases/news-releasedetails/modernas-covid-19-vaccine-candidate-meets-its-primary-efficacy (accessed 26 March 2021).

6 'AZD1222 vaccine met primary efficacy endpoint in preventing COVID-19, (Astra Zeneca, Press Release on 23 November 2020) https://www.astrazeneca.com/media-centre/press-releases/2020/azd1222hlr.html (accessed 26 March 2021).

7 'Landmark moment as first NHS patient receives COVID-19 vaccination' (UK National Health Service, 8 December 2020) https://www.england.nhs.uk/2020/12/landmark-moment-as-first-nhs-patient-receives-covid-19-vaccination/ (accessed 26 March 2021).

8 'Covid-19 vaccine tracker' (Regulatory Affairs Professionals Society, updated on 1 April 2021) https://www.raps.org/news-andarticles/news-articles/2020/3/covid-19-vaccine-tracker (accessed 3 April 2021).

${ }^{9}$ Ilan Noy and Ami Neuberger, 'The big barriers to global vaccination: patent rights, national self-interest and the wealth gap' (The Conversation, 20 January 2021) https://theconversation.com/the-big-barriers-to-global-vaccination-patent-rights-national-selfinterest-and-the-wealth-gap-153443 (accessed 26 March 2021); E't Hoen, 'Protect against market exclusivity in the fight against COVID-19' (2020) 26 Nature Medicine, at 813.

${ }^{10}$ Communication from India and South Africa, 'Waiver from certain provisions of the TRIPS Agreement for the prevention, containment and treatment of COVID-19' (WTO, Council for TRIPS, 2 October 2020), IP/C/W/669.

${ }^{11}$ Ibid, para. 3 .

${ }^{12}$ Hannah Kuchler and Clive Cookson, 'Vaccines versus variants: will the world ever reach herd immunity?' (Financial Times, 23 May 2021) https://www.ft.com/content/b035ef5f-dc2a-44d5-bded-b6573347939a (accessed 27 May 2021).
} 
19 would be left to a WTO member's discretion, following the proposal. ${ }^{13}$ It has been strongly asserted that waiving IP Rights will not increase production and will not solve practical challenges required to battle the global public health crisis. ${ }^{14}$

International reaction to this proposal has been mixed. At first, high-income economies such as the UK, the US, Australia, Japan, Canada, Norway, and the EU vigorously objected to this idea, arguing that IP Rights are not the issue to the delay of vaccine roll-out. ${ }^{15}$ However, it has been shocking to the world that the US, under the Biden administration has recently reversed their initial stance to support the proposal. ${ }^{16}$ This move has added considerable momentum in the current discussion over the initiative, given the US's global leadership role and the country's long-standing view as a patent aficionado. While the US's change of heart has been met with welcome and enthusiasm from the waiver supporters, President Biden's move is considered an "empty gesture". ${ }^{17}$ The country was stockpiling tens of millions of the AstraZeneca Vaccine, although the US Food and Drug Administration has not approved its use in the country at the time this was written. ${ }^{18}$ However, the crisis in India has pressured the US to share millions of doses.

The US's U-turn on the waiver proposal also has adverse impact on the pharmaceutical industry. Pharmaceutical firms' shares from the East to the West have dropped over night. ${ }^{19}$ According to the Guardian, the Hong Kong-listed shares of CanSino Biologics, were down nearly 22\%, while its Shanghai shares lost $17 \% .{ }^{20}$ Fosun Pharma, which distributes the BioNTech vaccine, fell by up to $18 \%$ in Hong Kong. ${ }^{21}$ Moderna and Novavax fell $6 \%$ and $5 \%$, respectively. ${ }^{22}$

What distinguishes this proposal from previous access to medicine campaigns is that a number of low and middle-income countries, for example, Chile, Mexico, and Brazil expressed their opposition to the

\footnotetext{
${ }^{13}$ Communication from The Plurinational State of Bolivia, Eswatini, India, Kenia, Mozambique, Mongolia, Pakistan, South Africa, The Bolivarian Republic of Venezuela and Zimbabwe, 'Waiver from Certain Provisions of the TRIPS Agreement for the Prevention, containment and Treatment of Covid-19 - Responses to Questions.' (WTO, Council for Trade-Related Aspects of Intellectual Property Rights, 15 January 2021), IP/C/W/672, page 6.

${ }^{14}$ Reto Hilty et al. 'Covid-19 and the Role of Intellectual Property Position Statement of the Max Planck Institute for Innovation and Competition of 7 May 2021' (The Max Planck Institute for Innovation and Competition) https://www.ip.mpg.de/en/publications/details/covid-19-and-the-role-of-intellectual-property-position-statement-of-the-maxplanck-institute-for-innovation-and-competition-of-7-may-2021.html (accessed 10 May 2021). See further the list of supporters supporting the Position Statement https://www.ip.mpg.de/en/research/research-news/covid-19-and-the-role-of-intellectualproperty-list-of-supporters.html (accessed 27 May 2021)

15 AD Usher, 'South Africa and India push for COVID-19 patents ban' (2020) The Lancet 396, 1790, 1790-1791; J Bacchus, 'An Unnecessary Proposal: A WTO Waiver of Intellectual Property Rights for COVID-19 Vaccines' (Free Trade Bulletin No. 78 of Cato Institute, 16 December 2020) https://www.cato.org/free-trade-bulletin/unnecessary-proposal-wto-waiver-intellectualproperty-rights-covid-19-vaccines accessed 29 March 2021. See issues raised by the UK, the US, the EU and Switzerland in Communication from The Plurinational State of Bolivia, Eswatini, India, Kenia, Mozambique, Mongolia, Pakistan, South Africa, The Bolivarian Republic of Venezuela and Zimbabwe, 'Waiver from Certain Provisions of the TRIPS Agreement for the Prevention, containment and Treatment of Covid-19 - Responses to Questions.' (WTO, Council for TRIPS, 15 January 2021), IP/C/W/672.

16 Office of the United States Trade Representative, Press Office (05 May 2021) https://ustr.gov/about-us/policy-offices/pressoffice/press-releases/2021/may/statement-ambassador-katherine-tai-covid-19-trips-waiver (accessed 10 May 2021).

17 'Ten million reasons to vaccine the world' (The Economist, $15^{\text {th }}$ May 2021 edition).

18 Noah Weiland and Rebecca Robbins, 'The U.S. Is Sitting on Tens of Millions of Vaccine Doses the World Needs' https://www.nytimes.com/2021/03/11/us/politics/coronavirus-astrazeneca-united-states.html (The New York Times, 11 March 2021).

19 Julia Kollewe, 'Pharmaceutical firms' shares tumble after US plans patent waiver on Covid vaccines' (the Guardian, 6 May 2021) https://www.theguardian.com/business/2021/may/06/pharmaceutical-firms-shares-tumble-after-us-plans-for-patent-waiver-oncovid-vaccines (accessed 10 May 2021)

${ }^{20}$ Ibid.

${ }^{21} \mathrm{Ibid}$.

${ }^{22}$ Ibid.
} 
waiver of IP Rights, demanding a more data-driven solution. ${ }^{23}$ These countries require patent opponents to provide examples where the IP system has actually impaired the manufacture of COVID-19 related medicines and technologies, and the extent to which the waiver under members' IP laws will give rise to the widening of the access to COVID-19 vaccines. ${ }^{24}$

It is noteworthy that while Brazil and India were the leading voices of the developing countries during the TRIPS negotiations opposing the expansion of patents to pharmaceuticals, these two distant neighbours now grow apart in the current affair. Brazil argued that the proposed waiver is unnecessary because TRIPS already provided sufficient flexibilities for member states to combat public health. ${ }^{25}$ The contention amongst low-and middle-income countries regarding the role of IP Rights, including patents, in the global vaccine program is arguably evidenced by some countries not viewing them as an obstacle to access COVID-19 related treatment.

In the discussion over the waiver proposal, the age-old argument of patent rights vs patient rights has now been reinvigorated; all of them are reminiscent of the HIV/AIDS debate which took place two decades ago. Those supporting the waiver proposal have argued that patent holders are self-interested, lack morals and that in times such as these, they should offer a helping hand to other less fortunate countries. ${ }^{26}$ Eliminating COVID-19 related IP Rights is, therefore, considered a way of going forward. This paper refutes this accusation, claiming that neither patents nor other forms of IP Rights, but rather the sophisticated vaccine manufacture and trade restrictions have been the bottlenecks to vaccine distribution. The pandemic has one more time thrust the patent system into the limelight. In times where the world is faced with difficulties and uncertainties, it seems easy to point the finger at patents, turning it into a scapegoat.

It occurs to the authors of this paper that the proposal is built on a premise that once the patent system and other forms of IP Rights are dismantled, COVID-19 vaccines will be made cheaper and quicker. This is simply not true as research has pointed out that second-generation vaccines do not lead to the same price reduction than with generic drugs because the main cost drivers for vaccine development are fixed. ${ }^{27}$

\footnotetext{
23 See Chile and Mexico' opinions at Communication from Australia, Canada, Chile, and Mexico, 'Questions on Intellectual Property Challenges Experienced by Members in relation to Covid-19.' (WTO, Council for TRIPS, 27 November 2020), IP/C/W/671. See questions asked by Brazil in Communication from The Plurinational State of Bolivia, Eswatini, India, Kenia, Mozambique, Mongolia, Pakistan, South Africa, The Bolivarian Republic of Venezuela and Zimbabwe, 'Waiver from Certain Provisions of the TRIPS Agreement for the Prevention, containment and Treatment of Covid-19 - Responses to Questions.' (WTO, Council for Trade-Related Aspects of Intellectual Property Rights, 15 January 2021), IP/C/W/672, pp. 11-12, at 14.

${ }^{24}$ Ibid.

25 'Brazil: Support Wider Vaccine Production at WTO. Waiving Some Intellectual Property Rules is Crucial for Faster, More Equitable Access' (Human Rights Watch, 9 March 2021) https://www.hrw.org/news/2021/03/09/brazil-support-wider-vaccineproduction-wto (accessed 12 April 2021).

26 'Countries obstructing COVID-19 patent waiver must allow negotiations to start' (MSF, Press Release, 9 March 2021) https://www.msf.org/countries-obstructing-covid-19-patent-waiver-must-allow-negotiations (accessed 3 June 2021).

27 Aurelia Nguyen and Nina Schwalbe, 'Apples and oranges? Can second generation vaccines become as low cost as generic medicines?’ (2019) 37 Vaccine 2910, at 2911.
} 


\section{Understanding Vaccines and the Manufacturing Process}

Vaccines are biological products, which are produced with help from a microorganism and involve the manipulation of genetic material and living animal, bacterial, or yeast cell cultures. Compared to small molecule drugs which have generics, there is no such thing as generic vaccines, only so-called bio-similars (highly similar in terms of structure, function, and clinical effect to the innovator product). ${ }^{28}$ In the case of small molecule medicines, generic manufacturers can skip the clinical trial stage by demonstrating the bioequivalence of the copied medicine and the patented drug. Bioequivalence means that the active ingredient of a generic must be the same as that of the originator, and typically with no more than $20 \%$ deviation in efficacy. ${ }^{29}$ As conducting clinical trials is the most expensive and time-consuming phase during the process of making small molecule drugs, eliminating this stage will usually save generic manufacturers a significant amount of money, driving down the cost of the generics.

Meanwhile, in the case of vaccines, bioequivalence cannot be shown because every new vaccine is a new biological entity, whether or not it is manufactured through the same technology as previously available vaccines. ${ }^{30}$ Being a biological product makes vaccines more sensitive to heat and susceptible to microbial contamination. Therefore, even the simplest of biologicals must go through clinical trials, the step that can be bypassed in the case of small molecule medicines, because efficacy and safety cannot be determined by simple bioequivalence. All vaccines need to go through human studies and bear related costs in order to be registered. ${ }^{31}$ Having to conduct clinical trials is one of the reasons why the second generation COVID-19 vaccine is unlikely to be cheaper as it is the case for generic medicines.

From a standpoint of manufacturing, according to Vaccines Europe, a specialised group within the European Federation of Pharmaceutical Industries and Associations (EFPIA), it normally takes between 12 and 36 months to manufacture a vaccine once it has been tested and approved, in which quality controls are applied throughout the manufacturing process and represent up to $70 \%$ of the manufacturing time. ${ }^{32}$ Any changes, even subtle, in the production process whether in scale, process, or presentation may alter the final product and affect its purity, safety, or efficacy. Therefore, such changes must themselves be validated and approved again by regulatory authorities to prove that it does not alter the quality of the final product before widespread implementation. ${ }^{33}$ For complex vaccines, hundreds of quality control checks are required for approval of each batch. ${ }^{34}$ Also, vaccine manufacture must take place in a registered manufacturing facility

\footnotetext{
28 Ibid.

${ }^{29}$ Min Ding, 'The Pharmaceutical Industry: Specificity, Challenges, and What You Can Learn from this Book' in Min Ding and others (eds), Innovation and Marketing in the Pharmaceutical Industry: Emerging Practices, Research, and Policies (Springer 2014), at 9.

${ }^{30}$ Supra note 27, at 2912.

31 Ibid.

32 'How are vaccines produced' (Vaccines Europe, 24 June 2020) https://www.vaccineseurope.eu/about-vaccines/how-arevaccines-produced (accessed 3 April 2021).

${ }^{33}$ Ibid.

${ }^{34}$ Supra note 27 , at 2911.
} 
and follow Good Manufacturing Practice and Good Distribution Practice, which is also a significant challenge. ${ }^{35}$

In fact, before the approval of COVID-19 vaccines, in May 2020, a group of Imperial College's researchers foresaw that normal supply chain routes and distribution networks may face disruption, particularly because not a single of 200 vaccine manufacturing facilities worldwide was ready to produce a COVID-19 vaccine (at that time). ${ }^{36}$ In light of the complexity of the vaccine technology and the immediacy of the demand, the efforts made by manufacturers to scale up their production capacity from zero to 10bn should be seen as remarkable.

Today, on average it takes between 90 and 120 days to make a single batch of COVID-19 vaccine with the hope to reduce it to 60 days. ${ }^{37}$ For Pfizer-BioNTech, a batch can make anywhere from 1 to 3 million doses of vaccine per production run. ${ }^{38}$ Currently, the world potentially needs 12 to 15 billion doses to cover the entire world's population. In such a situation, only rapid, large-scale manufacture of vaccines is the key to regaining our freedom and normality, however this needs to be achieved without compromising the high level of quality assurance.

Given the complexity of the vaccine industry and manufacturing process, it takes between 5 to 10 years to build manufacturing capacity to standardize the local industry to comply with international standards. Expediting the construction of green-field facilities may also prove difficult due to the same conundrum seen in other capital-intensive industries such as mining of commodities or computer chip manufacture, namely, will market conditions by the time the facility comes on-line (years down the line) be attractive enough to generate adequate return on investment. ${ }^{39}$

In short, compared to other many traditional therapeutics, vaccine manufacture is one of the most challenging industries both in terms of their components and the technologies required to produce them. The complexity and sophistication of manufacture, the stringency of quality assurance and control, and regulations lead to a massive capital outlay and production cost to set up a manufacturing facility in the industry. These requirements are considered as barriers to market entry for new manufacturers. ${ }^{40}$ The vaccine market is, therefore, relatively small, compared to the pharmaceutical industry, which manufactures small molecule medicines (drugs).

The authors of this paper, therefore, maintained that roadblocks of the inoculation program have nothing to do with IP Rights but lie in manufacturing, supply chain, and transportation. Both Pfizer and Moderna vaccines are fragile products; they must remain frozen during shipping, with the Pfizer requiring

\footnotetext{
35 John Smeaton \& Lydia Harriss, 'Rapid response: Manufacturing COVID-19 vaccines' (The UK Parliament, 14 January 2021) https://post.parliament.uk/manufacturing-covid-19-vaccines/ (accessed 4 April 2021).

${ }^{36} \mathrm{~S}$ West et al., 'Is the world ready to produce a billion doses of a COVID-19 vaccine?' (Imperial College London, News on 6 May 2020) https://www.imperial.ac.uk/news/197321/is-world-ready-produce-billion-doses/ accessed 5 April 2021.

37 'Towards Vaccinating The World' (IFPMA, 9 March 2021), 6 https://www.ifpma.org/wpcontent/uploads/2021/03/Summit_Landscape_Discussion_Document.pdf (accessed 19 April 2021).

${ }^{38} \mathrm{E}$ Weise and K Weintraub, 'A COVID-19 vaccine life cycle: from DNA to doses' (USA Today News, 8 February 2021) https://eu.usatoday.com/in-depth/news/health/2021/02/07/how-covid-vaccine-made-step-step-journey-pfizer-dose/4371693001/ (accessed 19 April 2021).

39 'Chipmaking is being redesigned. Effects will be far-reaching' (The Economist, 21 January 2021).

${ }^{40}$ Supra note 27, at 2911.
} 
unusually cold storage temperatures (-70 degrees Celsius). The sluggish vaccination campaign in the EU has been mainly attributed to manufacturing issue (and to many more non-IP factors such as vaccine scepticism) ${ }^{41}$

The export restrictions imposed by the EU and the US have also worsened the situation. Particularly, the US Defence Production Act of 1950 allows for the rating of specific medical items and reserves them to produce vaccines for Americans. While it seems evident why the country's government would want to prioritise their populations, this approach has created a knock-on effect on the availability of special inputs from plastic tubing, filters and even specialist bags to manufacture the vaccine. The ban has made those items become in short supplies outside of the US and as a result, this has caused more disruptions. While endorsing the waiver proposal could be seen as a good PR message for the Biden administration which is to paint the US's action as a moral imperative, a more effective and needy solution could have been lifting the ban to speed up vaccine manufacture.

Poor countries are also far from blameless. The Indian government's decision to temporarily ban exports of AstraZeneca's vaccine, which is being manufactured by the Serum Institute of India, the world's biggest vaccine maker, hit other poorer countries badly. Ironically, India, the country which co-authored the waiver proposal tabled at the TRIPS Council, cannot escape from vaccine nationalism.

Such abovementioned trade restrictions have made a dent in vaccine supplies where there is essential interdependency across all vaccine manufacturers for critical inputs. For example, manufacturing Pfizer vaccine involves " 280 components, 86 suppliers, 19 countries". ${ }^{42}$ Therefore, "lack of availability of a single component could halt the entire production process and may force the scrapping of a batch that might already have been in production for several weeks." ${ }^{43}$

Likewise, a report of the UK Parliament identified that one of the main roadblocks that slow COVID19 vaccine manufacture is the final "fill and finish" stage, i.e., putting the vaccine into containers for distribution, which can be understood as the "bottling" of a product. ${ }^{44}$ As a normal practice, large vials usually contain 10 or even 20 doses of a vaccine, but this approach cannot meet the current demand of transporting the number of COVID-19 vaccines required for global scale vaccination. ${ }^{45}$

The challenges to vaccine manufacture are real and enormous and for that reason, cooperation, not polarisation, must be needed to free the world from the pandemic and give back the normal life that many of us have missed.

\footnotetext{
41 'Covid: What's the problem with the EU vaccine rollout?' (BBC, 4 March 2021) https://www.bbc.co.uk/news/explainers$\underline{56286235}$, accessed 22 March 2021. See further at 'The lack of needles and the damage done. Why the EU's covid-19 vaccination programme went wrong' (The Economist, 3 April 2021).

42 Marie O'Halloran, 'Taoiseach warns against global interruption of vaccine delivery' (The Irish Times, 24 March 2021) https://www.irishtimes.com/news/politics/taoiseach-warns-against-global-interruption-of-vaccine-delivery-1.4518904 (accessed 10 May 2021).

${ }^{43}$ Supra note 37, at 7.

${ }^{44}$ Supra note 35.

${ }^{45}$ Supra note 36.
} 


\section{Eroding Patent Protections Does More Harm than Good}

The inherent sophistication of vaccine manufacture has turned IP Rights into a low hanging fruit where it is easy to be (wrongfully and factually) blamed. We need to acknowledge the fact that vaccine roll-out is not a single-faceted issue of IP Rights but a multi-dimensional problem where know-how, access to manufacturing facilities, labour intensity, expertise, distribution system and logistical challenges are jointly required to accelerate the global vaccination.

Vaccine development is a highly risky, uncertain, and capital-intensive business. It has an average of $94 \%$ chance of failure, meaning that only $6 \%$ of vaccine candidates have proved successful. ${ }^{46}$ This figure is much lower than the success rate (the likelihood that a drug that enters clinical testing will eventually be approved) of small molecule drugs, which is $11.83 \% .{ }^{47}$ Meanwhile, the estimated cost per approved new vaccine varies between $\$ 1.2$ billion and $\$ 8.4$ billion, ${ }^{48}$ which is unusually high compared with the cost of finding a new drug, ab initio, which is almost $\$ 1.4$ billion. ${ }^{49}$

Because of the innate vulnerability of the vaccine industry due to the uncertain outcomes of clinical trials, changes in epidemiology and in many other aspects, IP Rights including the patent system have long been regarded as a guarantee of return on $R \& D$ investment, only if the vaccine is proved successful. Pharmaceutical companies have maintained that where there is insufficient or no patent protection, free rides on the efforts of innovators occur frequently. They argue that without patents, the incentive for pharmaceuticals innovations would be weakened, these companies would bear all the cost and run the risk. While the patent system is not proven to be an incentive to innovation in certain industries, the case of the pharmaceutical industry is radically different. Without a reliable patent system, there is no incentive to invest.

With regards to the pandemic, some pharmaceutical companies have pledged not to sell their vaccines to make profit but rather, to only cover their costs and have agreed on set prices with the government, with Astra Zeneca selling their doses as low as $£ 3 .{ }^{50}$ While some manufacturers only start to see a return on their investment, contrastingly, AstraZeneca, despite being the biggest supplier at the moment, only covers its costs. ${ }^{51}$ Out of almost $£ 19$ billion which had been invested in vaccine development, $£ 6.5$ bn came from government funding, nearly $£ 1.5 \mathrm{bn}$ from not-for-profit organisations with the largest contribution of approximately $£ 12$ billion borne by the private sector thus amounting to $60 \%$ of total spending. ${ }^{52} \mathrm{Mr}$. Cueni, the director general of the IFPMA, while agreeing that governments' financial support helps accelerating

\footnotetext{
${ }^{46}$ Dimitrios Gouglas et al., 'Estimating the cost of vaccine development against epidemic infectious diseases: a cost minimisation study' (2018) 6 Lancet Global Health 1386, at 1386.

47 Joseph A DiMasi et al., 'Innovation in the Pharmaceutical Industry: New Estimate of R\&D cost' (2016) 47 Journal of Health Economics 20, at 23.

48 Supra note 46 , at 1386.

${ }^{49}$ Supra note 47 , at 26.

${ }^{50}$ Lucy Hooker and Daniele Palumbo, 'Covid Vaccines: Will Drug Companies Make Bumper Profits? (BBC, 18 December 2020), https://www.bbc.co.uk/news/business-55170756 (accessed 3 June 2021).

${ }^{51}$ Ibid.

${ }^{52}$ Ibid.
} 
the development of COVID-19 vaccines, "the R\&D were still driven by scientists in the private sector. Furthermore, governments have neither the money nor the risk tolerance to take over the role of businesses in developing pharmacy-ready medicines. ${ }^{53}$ Where some profits are incurred by companies, it is to be borne in mind that private firms could have never devoted their entire resources to the creation of a vaccine for a public health emergency. In general, the pharmaceuticals industry is one of a very few areas that show the greatest sensitivity to patents. Taylor and Silberston's study in 1973 found that pharmaceuticals showed an extreme reaction to patent protection, that is, patent-based production occupied a significant share - $68 \%$ of the total sales. ${ }^{54}$

Mansfield's study in 1986 similarly concluded that without a patent system $60 \%$ of medical inventions could not have been developed and $65 \%$ could not have been commercially introduced. In contrast, figures for chemicals were $30 \%$ and $38 \%$ respectively, and $18 \%$ and $25 \%$ for petroleum, respectively. ${ }^{55}$

In the same vein, in 1987 Levin et al., confirmed that the pharmaceutical industry was the only industry in which product patents were considered as strictly more effective than other means of appropriation. ${ }^{56}$ Other sectors, such as aircraft and computers, showed patents to be of little effect. ${ }^{57}$

Sharing the same finding, in 2000 Cohen et al. considered that patents for drugs (and medical equipment) accounted for more than $50 \%$ of product innovations. ${ }^{58}$ The pharmaceutical industry applied for patents for more than two-thirds of their products and more than $40 \%$ of their processes. ${ }^{59}$ These numbers are quite high in comparison to other industries, such as food, textiles, glass, steel and other metals, where patents were applied for in the case of less than $15 \%$ of products $^{60}$.

While it is not certain whether implementation of the waiver proposal would bring any desirable outcomes to vaccine distribution, such a radical move would potentially disincentivise vaccine development to respond to new COVID-19 variants. Manufacturing vaccines is a complex process when compared to medicines. While drugs are given to treat, diagnose or, to a more limited extent, prevent diseases, vaccines are given mostly to prevent diseases. This is a challenging task since manufacturers cannot predict the global epidemiological profile.

Awarding protection for inventions and later disclosing them to the world at large motivates people's creativity. A comprehensive waiver of all IP Rights relating COVID could backfire on the society if the IP holders decide to discontinue research as a result of such a waiver. ${ }^{61}$ The patent system yields great benefits

53 Thomas Cueni, 'The Risk in Suspending Vaccine Patent Rules' (The New York Times, 10 December 2020) https://www.nytimes.com/2020/12/10/opinion/coronavirus-vaccine-patents.html accessed 15 April 2021.

${ }^{54}$ Christopher Thomas Taylor and Aubrey Silberston, The Economic Impact of the Patent System: A Study of the British Experience (CUP 1973) 201.

55 Edwin Mansfield, 'Patents and Innovation: An Empirical Study' (1986) 32 Management Science 174.

${ }^{56}$ Richard C. Levin et al., 'Appropriating the Returns from Industrial Research and Development' (1987) 3 Brookings Papers on Economic Activity 783, at 796.

${ }^{57}$ Ibid., at 797.

${ }^{58}$ Wesley M. Cohen et al., 'Protecting Their Intellectual Asserts: Appropriability Conditions and Why the US Manufacturing Firms Patent (Or Not)' (2000) NBER Working Paper No. 7552, 9 http://www.nber.org/papers/w552 (accessed 19 April 2021).

${ }^{59}$ Ibid., at 16.

${ }^{60}$ Ibid.

${ }^{61}$ Supra note 14 at 5. 
but often these benefits occur in the long term. ${ }^{62}$ Therefore, those benefits are difficult to confirm and harder to quantify. Take the Pfizer-BioNTech vaccine as an example. This is the first truly successful application of mRNA vaccine, but it is not widely known that the founding couple of BioNTech have started this technology more than 25 years ago and founded their company in $2008 .{ }^{63}$

It is true that vaccinating the world speedily is the only way to put an end to the pandemic, but it is equally true that through the patent system, pharmaceutical companies, research institutes and countries' governments have collaborated at an unprecedented speed to develop different COVID vaccines that have been approved. ${ }^{64}$ It is not an exaggeration to state that the IP system is in itself, the fundament to such collaboration. Although the patent system has been the object of severe criticism, cold water should not be poured on the importance of patents.

It is naïve to believe that taking an antagonistic approach toward IP Rights will speed up vaccine production. Rajinder Suri, the Chief Executive Officer of Developing Countries Vaccine Manufactures Network (DCVMN) and Sai Prasad, the President of Bharat Biotech, an Indian vaccine manufacturer assented that removing IP Rights will not solve challenges in vaccine manufacture as practical issues lie in non-IP factors including, inter alia, human resources, manufacturing capacity, know-how. ${ }^{65}$ The Gates Foundation, which poured billions of pounds into the R\&D of vaccines echoed the view that technology transfer, not patents, is the main roadblock to expanding vaccine production. ${ }^{66}$ The Max Planck Institute for Innovation and Competition in their recent position statement also endorses the view that "IP rights might so far have played an enabling and facilitating rather than hindering role in overcoming Covid-19, and that the global community might not be better off by waiving IP rights, neither during nor after the pandemic" ${ }^{67}$

Importantly, as vaccine manufacture requires significant knowledge of know-how or trade secrets, ${ }^{68}$ which act as a high barrier to entry for new manufacturers, this information is, nevertheless, not disclosed in patent applications. The waiver proposal is, therefore, unlikely to force the rights holders to share these non-registered IP Rights. Even with no IP protection and the ability for companies to make COVID-19 vaccines, the question that needs to be asked is would an additional generic company embark on a highly risky and research-intensive business without certain outcomes? The answer is probably no. It is evidenced that Moderna pledged not to enforce their COVID-19-related patents ${ }^{69}$ but no manufacturer seized this opportunity to make the Moderna vaccine. This is to say that making COVID-19 vaccines is not an easy

\footnotetext{
62 Hon Maureen K. Ohlhausen, 'Patent Rights in a Climate of Intellectual Property Skepticism' (2016) 30(1) Harvard Journal of Law \& Technology 103, 105.

63 Thomas Cueni, 'The Risk in Suspending Vaccine Patent Rules' (The New York Times, 10 December 2020) https://www.nytimes.com/2020/12/10/opinion/coronavirus-vaccine-patents.html (accessed 15 April 2021).

${ }^{64}$ Supra note 8

${ }^{65}$ See 'Virtual Press Briefing following the Global COVID-19 Vaccine Supply Chain \& Manufacturing Summit' (IFPMA 9 March 2021) at 19'02 - 25'23 where the matter of IP Rights was being discussed https://www.ifpma.org/resource-centre/virtual-pressbriefing-following-the-global-covid-19-vaccine-supply-chain-manufacturing-summit-video/ (accessed 5 April 2021).

${ }^{66}$ Svět Lustig Vijay \& Elaine Ruth Fletcher, 'Gates Foundation: Technology Transfer, Not Patents Is Main Roadblock To Expanding Vaccine Production' (Health Policy Watch, 14 April 2021) https://healthpolicy-watch.news/patents-are-not-main-roadblock-toexpanding-vaccine-production-says-top-gates-foundation-official/ (accessed 19 April 2021).

${ }^{67}$ Supra note 14.

${ }^{68}$ David S. Levine, 'Trade secrets and the battle against Covid' (2020) 15(11) Journal of Intellectual Property Law \& Practice 849, 849-850.

69 'Statement by Moderna on Intellectual Property Matters during the COVID-19 Pandemic' (Moderna, 8 October 2020) https://investors.modernatx.com/node/10066/pdf (accessed 10 May 2021).
} 
task for anyone. Even the UK, the host country of the AstraZeneca vaccine, has limited facilities for vaccine manufacture, although it does possess the capacity to make vaccines for influenza and some childhood diseases. ${ }^{70}$ This pandemic has exposed a bitter truth that even rich countries such as Germany, the US, which host patent holding companies, are struggling with vaccinating their own population. Vaccination is, in fact, a universal issue.

It is crucial to emphasise that, in light of the COVID-19 pandemic, not only low-and middle-income countries like Chile or Ecuador but also high-income nations such as Israel, France, Canada, Germany have taken legislative steps to employ compulsory licensing when the treatment for COVID-19 was found. ${ }^{71}$ Nevertheless, not a single compulsory licence has been issued so far. Neither has a request for a voluntary licence been made. This paper claims that the absence of vaccine manufacturing capacity is the biggest reason behind such inaction. As analysed above, the vaccine manufacturing process requires highly sophisticated technology and rigorous quality control to preserve its safety and efficacy. Therefore, removing the entire ecosystem of IP Rights is, indeed, attacking the wrong root cause. Even India, the coauthor of the proposal in an affidavit to the Indian Supreme Court dated 9 May 2021 has confessed that even discussions or a mention of exercising governmental power for essential drugs or vaccines that has patent protection "would have serious, severe and unintended adverse consequences" and "any exercise of statutory powers $[\ldots]$ can only prove to be counter-productive at this stage." 72

The fear of COVID-19 vaccine monopoly is also unreasonable as currently thirteen vaccines have been approved, with sixty candidates in development. ${ }^{73}$ Therefore, we can be optimistic that the market of COVID-19 vaccines will become more competitive in the very near future. The authors of this paper argued that the waiver proposal could take months to be adopted and then implemented as this decision must be consensus-based and WTO member countries will need to amend their domestic laws. Such effort should be directed to solve practical issues of vaccine manufacture. While time, which is of the essence, is spent on negotiating the proposal text, the COVID-19 virus will be mutating.

Eroding IP Rights including the patent system will send a bad signal to the investors who might reconsider the investment in exploring uses of future vaccine technology such as mRNA. At a time when the world's epidemiological profiles can fluctuate and vary unpredictably, what we need is more funding for research. The comprehensive waiver of all IP Rights does not at all reflect the stark reality, which is that coronaviruses mutate swiftly and are more deadly. The proposal put forward by India and South Africa will likely have the deleterious effects on current COVID-19 research.

Furthermore, dismantling patent protection might lead to substantial risks. First of all, if patented vaccines are in the public domain and are not properly allocated, the ripple effect of the tragedy of common goods will soon be felt. Complex vaccine manufacture requires deep partnership between developers, manufacturers, and suppliers. As has been repeatedly stressed in this article, vaccines, particularly like the

\footnotetext{
${ }^{70}$ Supra note 35.

${ }^{71}$ Martina Dani, 'Public health comes first' (2020) 15(11) Journal of Intellectual Property Law \& Practice 865.

${ }^{72}$ In the Supreme Court of India Civil Original Jurisdiction Suo Motu Writ petition (C) NO.3/2021 dated 9 May 2021, in the Matter of: Distribution of Essential Supplies and Services During Pandemic, at 65-66 https://www.livelaw.in/pdf_upload/centres-affidavitin-suo-moto-covid-case-supreme-court-393164.pdf (accessed 16 May 2021).

73 Supra note 8.
} 
ones from Pfizer and Moderna (using messenger RNA technology) require stringent and labour-intensive quality assurance processes that even existing manufacturers have trouble sourcing. If patent holders either refuse to transfer their marketing authorisation licence or help local partners in obtaining marketing authorisation (by sharing required data and know-how) ${ }^{74}$ or cannot implement certain quality controls as a result of the IP waiver, ineffective vaccines manufactured using substandard processes could undermine public confidence in them. In fact, rapid R\&D of COVID-19 vaccines has cast doubt on their efficacy and safety. For example, in an international survey of attitudes towards Covid vaccination, Polish respondents exhibited the highest proportion of negative responses. ${ }^{75}$ In December 2020, $44 \%$ of Poles said that they would refuse if being offered a jab. ${ }^{76}$ In France, just $42 \%$ of people answering a poll said they would take the vaccine. ${ }^{77}$ One in three French people thinks vaccines, in general, are unsafe - the highest figure for any country. ${ }^{78}$ Speeding up vaccine manufacture must not be done at the expense of quality, efficacy and safety of vaccines.

Secondly, removing IP rules can cause an increase in counterfeit products. While patents and other forms of IP Rights are generally viewed as an incentive to fuel innovation, it is little known that they also serve to suppress counterfeiting. The WHO has determined that counterfeiting is facilitated where "[...] there is lack of effective intellectual property protection". ${ }^{79}$ Counterfeit drugs are found everywhere, but sub-Saharan Africa is particularly affected. ${ }^{80}$ There have been examples in Cameroon and Uganda where fake Covid-related treatment has been found ${ }^{81}$ Consequently, dismantling the IP system can result in more spread of pharmaceutical crime.

\section{Conclusion}

Although the patent system is nowhere from being perfect and has its flaws, it is overly simplistic and unfair to shift the blame to patent protection and the global pharmaceutical companies for vaccine distribution. Annulling patents and other forms of IPRs on the false belief that they will accelerate the current slow vaccine roll-out is an illusory promise. While it is true that "no one is safe until everyone is safe", instead of trying to bring the whole IP system down, we should look into the vaccine situation from a more holistic view to identify the root cause of the problem. We should spend less time pointing the finger and rather move beyond condemning IP Rights. To truly address the problem, the focus now should be on removing real bottlenecks by lifting trade restrictions and finding ways to boost global manufacturing partnerships between vaccine makers and strengthening their cross-border supply chains. We should steer away from the

\footnotetext{
${ }^{74}$ Supra note 14 , at 5 .

${ }^{75}$ Ibid.

${ }^{76}$ Monika Sieradzka, 'Anti-vaccine sentiment rife in Poland' (Deutsche Welle, 31 December 2020) https://www.dw.com/en/antivaccine-sentiment-rife-in-poland/a-56100878 (accessed 4 April 2021).

77 'Pasteur's lament. Why France's vaccination roll-out has been so slow' (The Economist, 30 January 2021).

78 'Why is Europe so riddled with vaccine scepticism?' (The Economist, 10 December 2020).

79 WHO, 'Counterfeit Drugs: Report of a WHO/IFPMA Workshop. WHO/DMP/CFD/92' (1-3 April 1992) 11-12 https://apps.who.int/iris/bitstream/handle/10665/58358/WHO_DMP_CFD_92.pdf?sequence=1\&isAllowed=y (accessed 19 April 2021).

${ }^{80}$ Marius Schneider \& Nora Ho Tu Nam, 'Africa and counterfeit pharmaceuticals in the times of COVID-19' (2020) (15)6 Journal of Intellectual Property Law \& Practice 417, pp. 417-8.

${ }^{81}$ Ibid.
} 
decades-long debate over patents/IP Rights and access to medicine which has polarises the world where there is a need for unity. 